\title{
The impact of the universities closure on physical activity and academic performance in physical education in university students during the COVID-19 pandemic
}

\author{
Aleksander Yu. Osipov ${ }^{1,2 \mathrm{ABDE}}$, Tatyana I. Ratmanskaya ${ }^{1 \mathrm{BCDE}}$, Elena A. Zemba ${ }^{3 \mathrm{BDE}}$, Vladimir Potop ${ }^{4 \mathrm{BCE}}$, \\ Mikhail D. Kudryavtsev ${ }^{1,3 \mathrm{BCD}}$, Roman S. Nagovitsyn ${ }^{5 \mathrm{BCDE}}$ \\ ${ }^{1}$ Siberian Federal University, Russian Federation \\ ${ }^{2}$ Prof. Voyno-Yasenetsky Krasnoyarsk State Medical University, Russian Federation \\ ${ }^{3}$ Reshetnev Siberian State University of Science and Technology, Russian Federation \\ ${ }^{4}$ Ecological University of Bucharest, Romania \\ ${ }^{5}$ Glazov State Pedagogical Institute named after V.G. Korolenko, Russian Federation
}

\begin{abstract}
Background Physical activity (PA) is regarded as a critical component of a healthy lifestyle and disease prevention. and Study Different constraints placed upon social interaction and public spaces due to COVID-19 could decrease PA Aim and academic performance in physical education (PE) in student population. The purpose of the research was to assess overall and sport/fitness PA level and academic performance in PE in a sample of university students pre- to post-cancellation of face-to-face PE classes due to the COVID-19 pandemic.

Material Participants ( $\mathrm{n}=209)$ - university students (19-20 years old). The overall period of the research is Septemberand December 2020. All participants (male- $\mathrm{n}=106$ and female- $\mathrm{n}=103$ ) were divided into approximately equal Methods groups: humanities students (male-MG-1, female-FG-1), medicine students (male-MG-2, female-FG-2), technical students (male-MG-3, female-FG-3). The main research tools: modified student self-reported questionnaire (on the base of IPAQ), academic grading (scores for self-completed PE tasks). In surveys, all participants self-rated overall and sport/fitness PA level pre- to post-cancellation of face-to-face PE classes. The participants had to complete 32 special PE tasks, during the research period. PE teachers rated participants by a special grading scale.

Results: $\quad$ For the male and female students' groups there were no significant differences of overall PA, sport/fitness PA level and academic performance in PE pre-cancellation of face-to-face PE classes. All participants significantly $(p \leq 0.05)$ decreased overall PA, sport/fitness PA level and academic performance in PE postcancellation. There was a significant $(p \leq 0.05)$ large amount of overall PA level in MG-2 students and sport/ fitness PA level in MG-1 students' post-cancellation of face-to-face PE classes. For the male students there were no significant differences of grading in PE pre- to post-cancellation of face-to-face PE classes between participants groups. There was a significant $(p \leq 0.05)$ large amount of overall PA level post-cancellation of face-to-face PE classes in FG-2 students. There was a significantly $(p \leq 0.05)$ lower amount of sport/fitness PA level post-cancellation of face-to-face PE classes in FG-3 students. There was a significant drop in mean grading scores in PE post-cancellation of face-to-face PE classes in students. FG-2 participants had significantly $(p \leq 0.05)$ higher grading scores in PE post-cancellation of face-to-face PE classes.

Conclusions: The universities closure and cancellation of face-to-face PE classes due to the COVID-19 pandemic decreased overall PA, sport/fitness PA level and academic performance in PE in all participants. It is important to note that the proportional decrease in overall PA for the male students was actually large, then decrease in overall PA for the female students was less. The findings highlight the need for active interventions of PA promotion targeted at the student population in the context of self-isolation measures during the COVID-19 pandemic. Keywords physical activity, student population, COVID-19 pandemic, face-to-face PE classes, student survey, academic scores.
\end{abstract}

\section{Introduction}

Physical activity (PA) is regarded as a critical component of a healthy lifestyle and disease prevention. Regular PA helps maintain a healthy weight, reduces the risk of developing obesity, and strengthens the immune system [1]; conversely, physical inactivity increases the risk of many chronic diseases, such as hypertension, coronary heart disease, stroke, diabetes, depression, and risk of falls. A considerable amount of evidence suggests that the level of subjectively and objectively measured PA is in constant decline among young individuals [2,

(c) Aleksander Yu. Osipov, Tatyana I. Ratmanskaya, Elena A. Zemba, Vladimir Potop, Mikhail D. Kudryavtsev, Roman S. Nagovitsyn, 2021 doi:10.15561/20755279.2021.0103
3]. Researchers have identified that the prevalence of physical inactivity was significantly higher among youth compared to those individuals older than 25 years of age [4]. It is known that young people spend more time on electronic devices than other age groups $[5,6]$ that related to several health risks in adulthood. Sedentary behaviour is increasing among the youth population and is associated with numerous unhealthy outcomes [7]. Furthermore, the lack of physical activity is seen as a major threat for cognitive health in young adults. Investigators state the positive effects of PA interventions on cognitive outcomes and academic performance in young adults (schoolers and university students) [8]. Romanian scientists state 
that for trained student population, the overall level of PA difference between males and females was around $64 \%$ in MET minutes per week (6583 for male and 4103 for female university students) [9]. The controversial data on the PA level of Russian students are presented. Some Russian researchers state that positive trends engagement in regular PA in all age groups are recorded lately, and the number of individuals (including university students) regularly engaged in physical activities has been increasing every year [10]. Other experts note the low level of PA [11, 12] and physical fitness of students [13].

The coronavirus disease 2019 (COVID-19) is an infectious disease caused by a novel form of a coronavirus first discovered in 2019 and caused a global pandemic in the world. This is a new treat that affects the adaptive mechanisms of the human being what leads to affecting world population [14]. To prevent the spread of COVID-19, state and local governments enacted numerous restrictions on human movement and physical interactions. As a result, young individuals (school and university students) no longer had access to based physical activities such as physical education (PE), recess, youth team sports, and walking to/from school/university [15, 16]. Youth team sports leagues cancelled all practices and games. Investigators have possible that constraints placed upon social interaction and public spaces due to COVID-19 could decrease PA, increase sedentary behaviour, and subsequently increase bodyweight of different populations, including university students [17]. Home confinement could prevent students from achieving the physical activity and sleep levels recommended for their psychophysical health [18]. Ensuring sufficient levels of PA and reducing sedentary time can play a vital role in helping individuals to cope with a major stressful event, such as the COVID-19 pandemic [19]. It is known that PA induced anti-inflammatory cytokines production such as IL-10 and IL-6 suggesting the protective role of regular PA in viral infection and then in COVID-19 diseases [20].

Today there is an emerging body of scientific literature examining the potential impact of the COVID-19 upon PA of university students [21], but scientists still the need for more research on this topic. Sallis et al, state that this type of research is needed not only to inform better activity recommendations during the COVID-19 pandemic but for improved responses to similar events in the future [22]. The COVID-19 discontinue the classic style of higher education, forcing the teachers and students to adopt new methods of learning, which disrupt the learning process involving human interaction and transfer it to forced virtualization [23]. Investigators state that online communication has gained value and will be invaluable in new academic society during and post-COVID19. Potential of today's technological advances will enable for a change in PE teaching and sports practice, PA level, behaviour and quality of life of university students [24].

Investigators state that whole tertiary educational system has been collapsed during the lockdown period of the novel coronavirus disease 2019 (COVID-19) across the globe [25]. Online education (online learning) is one popular method being used by universities in various countries to meet the needs of social distancing during the COVID-19 pandemic. The differences in academic motivation between university students of traditional (inclassroom) and online (distance) education during the COVID-19 pandemic were investigated. Malinauskas \& Pozeriene, point that online (distance) students possess stronger intrinsic motivation in education than traditional (in-classroom) students. These scientists pointed that university students whose behaviour is mostly internally regulated (or autonomous) have more interest, confidence, persistence and better performance than students who are mostly externally controlled [26]. Tilga et al, state that autonomy-supportive behaviour was related to adolescents' and youth leisure-time PA participation. Scientists highlight the facilitative role of autonomy-supportive behaviour in a PE context on young individuals PA participation [27]. Nagovitsyn et al, state that high positive impact of the motivational-value attitude of university students to the implementation of PA by methods of introducing interactive technologies in theoretical and methodological exercises in the PE courses in higher education [28]. Spanish investigators conclude that COVID-19 confinement changed students' learning strategies to a more continuous habit, improving their efficiency. For this reason, better scores in students' assessment are expected due to COVID-19 confinement that can be explained by an improvement in their academic performance [29].

However, Russian researchers state that during distance learning in the framework of practical PE classes, there is a significant decrease in students' motivation to engage in PE and sports in education [30]. It is known that before the pandemic, most Russian university students did not use online learning in PE [31]. Investigators point to significant resistance of some PE teachers in terms of transition to distance learning models. The most of PE teachers consider direct contact between the teacher and student a necessary condition for successful learning [32]. Lavrin et al, point that most Ukrainian students supports the traditional form of $\mathrm{PE}$ classes in higher education [33]. Ukrainian investigators state that PE teachers were not prepared to conduct PE classes in optimal physical conditions during the COVID-19 pandemic and were not able to provide alternative, interesting for students, forms and ways of organizing individual fitness training that would allow maintaining morphofunctional indicators of physical health [34]. Romanian investigators highlighted that most of students were satisfied with the measures taken by the university during the lockdown period and the way the teaching-learning-assessment process in PE took place [35]. Borodavko et al, concluded that neither teachers nor students were ready for the transformation that took place in the field of education. The problems faced by the participants in the online educational process are both technical and psychological [36]. Questionnaires and surveys of Russian students show that distance learning negatively influenced the usual daily routine, 
level of daily PA, as well as vision and well-being [37].

In order to assess the academic performance in PE and PA level of university students during the COVID-19 pandemic in comparison with their previous PA habits, a research investigating their PA level and mean grading scores in PE pre to post-cancellation of face-to-face PE classes was designed. We hypothesized that all participants would report reduced overall PA and sport/ fitness PA level. Furthermore, because male students tend to be more physically active than female students, we hypothesized a greater reduction in overall PA and sport/ fitness PA level for female students versus male students. Also we hypothesized that the academic performance of all participants will not significantly change postcancellation of face-to-face PE classes.

The purpose of this research was to assess overall and sport/fitness PA level and academic performance in PE in a sample of university students pre- to post-cancellation of face-to-face PE classes due to the COVID-19 pandemic.

\section{Materials and Methods.}

\section{Participants}

The university students (19-20 years old) male $(n=424)$ and female $(n=411)$ participated in this study. All ethical principles were observed. The research did not include any experiments involving human or biological human samples. All participants gave informed consent to participate in the research and publish the results. The research complied with the Declaration of Helsinki and was approved by the ethics commission of the Institute of Physical Culture, Sport and Tourism (Siberian Federal University) in Russian Federation.

Research design

The bases of the research - large universities of the Russian Federation: Siberian Federal University (SFU), Prof. Voyno-Yasenetsky Krasnoyarsk State Medical University (KSMU) and Reshetnev Siberian State University of Science and Technology (RSSU). The overall research period was four months (SeptemberDecember 2020). At the first stage, the link to the survey was sent to potential participants between $8 / 28 / 20$ and $9 / 12 / 20$. In this survey, all respondents self-rated overall and sport/fitness PA level pre-cancellation of faceto-face PE classes. Any participant that was missing information for one or more of the items of interest in the survey (i.e., PA level pre-cancellation of face-toface PE classes, gender, age) was removed from the research. The final sample was $n=209(n=106$ male and $\mathrm{n}=103$ female). All participants (males and females) were divided into approximately equal groups at the second stage of the research (between $9 / 12 / 20$ and 12/28/20). The participant groups: SFU male students (MG-1), KSMU male students (MG-2), RSSU male students (MG-3). SFU female students (FG-1), KSMU female students (FG-2), RSSU female students (FG-3). SFU students studied humanities, KSMU students studied medicine and RSSU students studied technical specialties and engineering. The main research tools: modified student self-reported questionnaire (IPAQ), academic grading (scores for self- completed PE tasks).

The PA level of all participants was evaluated using International Physical Activity Questionnaire (IPAQ) in its modified version for this research (We have highlighted the questions for evaluating overall PA level and sport/ fitness PA level for participants in the research period. We didn't include in the questionnaire points for evaluating PA mobility, PA home and PA at work in connection with the pandemic). Administering the questionnaire to the participants took place trice, with an interval of one month (so that mean performance can be calculated). In each survey, all participants self-rated overall and sport/fitness PA level post-cancellation of face-to-face PE classes. The IPAQ results are presented in the spent total time of PA (minutes). Some participants had difficulty counting results at the MET (metabolic equivalent of task). Also, a more reliable comparison with data of other scientists (represented in time spent - minutes) was necessary.

All participants had to receive special PE tasks in the electronic educational environment of universities. All students had to send completed PE tasks to teachers for verification. The participants had to complete 32 special PE tasks, during the research period (two PE tasks per each week). Each PE task included theoretical material (questions or a test) and PE practice (performing physical exercises and movements). PE teachers rated participants by a five-score scale: 1 - bad score (not submitted PE task), 2 - low score (significant lack of theoretical information and significant errors in the technique of performing physical exercises), 3 - moderate score (some lack of theoretical information / delay in sending the PE task or significant errors in the technique of performing physical exercises), 4 - good score (insignificant lack of theoretical information or minor errors in the technique of performing physical exercises), 5 - excellent score (full theoretical information and no errors in the technique of performing physical exercises) for each completed PE task. We compared the participants' mean scores in PE with their mean scores' pre-cancellation of face-toface PE classes (the grades were taken from the official university academic records).

\section{Statistical Analysis}

The collected data were analysed using IBM SPSS Statistics for Windows 20.0 (Armonk, NY: IBM Corp.). All rates were expressed as means and standard deviations (SD). The reliability of differences in the findings was determined using the one-factor ANOVA test for independent measures (including post hoc Tukey HSD). The one-factor ANOVA test for repeated measures was performed to examine changes in time (pre- and postcancellation) indicators of the research. A $p$ value of $\leq 0.05$ was considered statistically significant.

\section{Results}

For the male university students there were no significant differences of overall PA and sport/fitness PA level pre-cancellation of face-to-face PE classes. There was a significant $(p \leq 0.05)$ changes in overall PA and sport/ fitness PA post-cancellation of face-to-face PE classes 
between participants groups. There was a significant $(\mathrm{p} \leq 0.05)$ large amount of overall PA level post-cancellation of face-to-face PE classes in MG-2 students. There were no differences of this indicator between MG-1 and MG-3 students. There was a significant $(\mathrm{p} \leq 0.05)$ large amount of sport/fitness PA level post-cancellation of face-to-face PE classes in MG-1 students. There were no differences of this rate between MG-2 and MG-3 students. For the male participants there were no significant differences of grading in PE pre- to post-cancellation of face-to-face $\mathrm{PE}$ classes between groups. The overall findings of the research for the male students are presented in Table 1.

There were no significant differences of overall PA and sport/fitness PA level pre-cancellation of face-toface PE classes for the female university students. There was a significant $(\mathrm{p} \leq 0.05)$ changes in overall PA level and sport/fitness PA level post-cancellation of face-toface PE classes between participants groups. There was a significant $(\mathrm{p} \leq 0.05)$ large amount of overall PA level postcancellation of face-to-face PE classes in FG-2 students. There were no differences of this indicator between FG-1 and FG-3 students. There was a significantly $(p \leq 0.05)$ lower amount of sport/fitness PA level post-cancellation of face-to-face PE classes in FG-3 students. There were no differences of this rate between FG-1 and FG-2 students. For the female students there were no significant differences of grading in PE pre-cancellation of face-toface PE classes between groups. There was a significant $(\mathrm{p} \leq 0.05)$ difference of grading in PE post-cancellation of face-to-face PE classes between participants groups. FG-2 participants had significantly $(\mathrm{p} \leq 0.05)$ higher grading scores in PE post-cancellation of face-to-face PE classes. There were no differences of this indicator between FG-1 and FG-3 students. The overall findings of the research for the female students are presented in Table 2.

There were a significant $(\mathrm{p} \leq 0.05)$ changes in academic performance in PE post-cancellation of face-to-face PE classes and universities closure in all participants. There was a significant drop in mean grading scores in PE post-cancellation of face-to-face PE classes in student population. Full information about the changes of mean grading scores in $\mathrm{PE}$ in participants pre- and postcancellation of face-to-face PE classes is presented in Fig. 1 (male participants) and in Fig. 2 (female participants).

Table 1. Mean PA rates and grading in PE pre- and post-cancellation of face-to-face PE classes for male participants.

\begin{tabular}{|c|c|c|c|c|}
\hline \multirow{2}{*}{ Indicators } & \multicolumn{2}{|c|}{ Participants - male students $(n=106)$} & \multirow[b]{2}{*}{ MG-3 (n=36) } & \multirow{2}{*}{$p \leq$} \\
\hline & MG-1 $(n=35)$ & MG-2 (n=35) & & \\
\hline \multicolumn{5}{|c|}{ Self-rated PA level (minutes per week) } \\
\hline Overall PA (A1) & $5116.62 \pm 285.17$ & $5089.48 \pm 238.36$ & $5095.42 \pm 304.11$ & 0.873286 \\
\hline Overall PA (A2) & $2651.34 \pm 322.25$ & $2868.51 \pm 266.43^{*}$ & $2634.75 \pm 267.39$ & 0.000144 \\
\hline Sport/fitness PA (A1) & $848.75 \pm 105.39$ & $837.46 \pm 95.21$ & $839.59 \pm 102.46$ & 0.912032 \\
\hline Sport/fitness PA (A2) & $306.12 \pm 45.23 *$ & $271.43 \pm 42.36$ & $273.49 \pm 38.27$ & 0.004555 \\
\hline \multicolumn{5}{|c|}{ Mean scores for completed PE tasks } \\
\hline Grading in PE (B1) & $4.27 \pm 0.45$ & $4.14 \pm 0.34$ & $4.21 \pm 0.39$ & 0.281290 \\
\hline Grading in $P E(B 2)$ & $3.78 \pm 0.41$ & $3.62 \pm 0.36$ & $3.65 \pm 0.44$ & 0.075035 \\
\hline
\end{tabular}

Note: * - p $\leq 0.05$ - (significance level); MG-1 - SFU male students; MG-2 - KSMU male students; MG-3 - RSSU male students; A1 - self-rated PA level (pre-cancellation of face-to-face PE classes); A2 - self-rated PA level (post-cancellation of face-to-face PE classes); B1 - mean scores (pre-cancellation of face-to-face PE classes); B2 - mean scores (postcancellation of face-to-face PE classes).

Table 2. Mean PA rates and grading in PE pre- and post-cancellation of face-to-face PE classes for female participants.

\begin{tabular}{|c|c|c|c|c|}
\hline \multirow{2}{*}{ Indicators } & \multicolumn{2}{|c|}{ Participants - female students ( $n=103$ ) } & \multirow[b]{2}{*}{ FG-3 (n=34) } & \multirow{2}{*}{$p \leq$} \\
\hline & FG-1 ( $n=35)$ & FG-2 (n=34) & & \\
\hline \multicolumn{5}{|c|}{ Self-rated PA level (minutes per week) } \\
\hline Overall PA (A1) & $2853.62 \pm 374.51$ & $2826.39 \pm 352.26$ & $2851.13 \pm 306.29$ & 0.887076 \\
\hline Overall PA (A2) & $2129.55 \pm 283.28$ & $2427.46 \pm 307.28 *$ & $2096.78 \pm 259.34$ & 0.000021 \\
\hline Sport/fitness PA (A1) & $504.62 \pm 72.34$ & $495.51 \pm 79.42$ & $497.85 \pm 64.26$ & 0.817412 \\
\hline Sport/fitness PA (A2) & $297.39 \pm 45.57$ & $294.38 \pm 39.23$ & $263.61 \pm 35.41 *$ & 0.001150 \\
\hline \multicolumn{5}{|c|}{ Mean scores for completed PE tasks } \\
\hline Grading in PE (B1) & $4.26 \pm 0.39$ & $4.35 \pm 0.47$ & $4.24 \pm 0.34$ & 0.922690 \\
\hline Grading in PE (B2) & $3.95 \pm 0.34$ & $4.17 \pm 0.32 *$ & $3.86 \pm 0.41$ & 0.000196 \\
\hline
\end{tabular}

Note: * - p $\leq 0.05$ - (significance level); FG-1 - SFU female students; FG-2 - KSMU female students; FG-3 - RSSU female students; A1 - self-rated PA level (pre-cancellation of face-to-face PE classes); A2 - self-rated PA level (post-cancellation of face-to-face PE classes); B1 - mean scores (pre-cancellation of face-to-face PE classes); B2 - mean scores (postcancellation of face-to-face PE classes). 


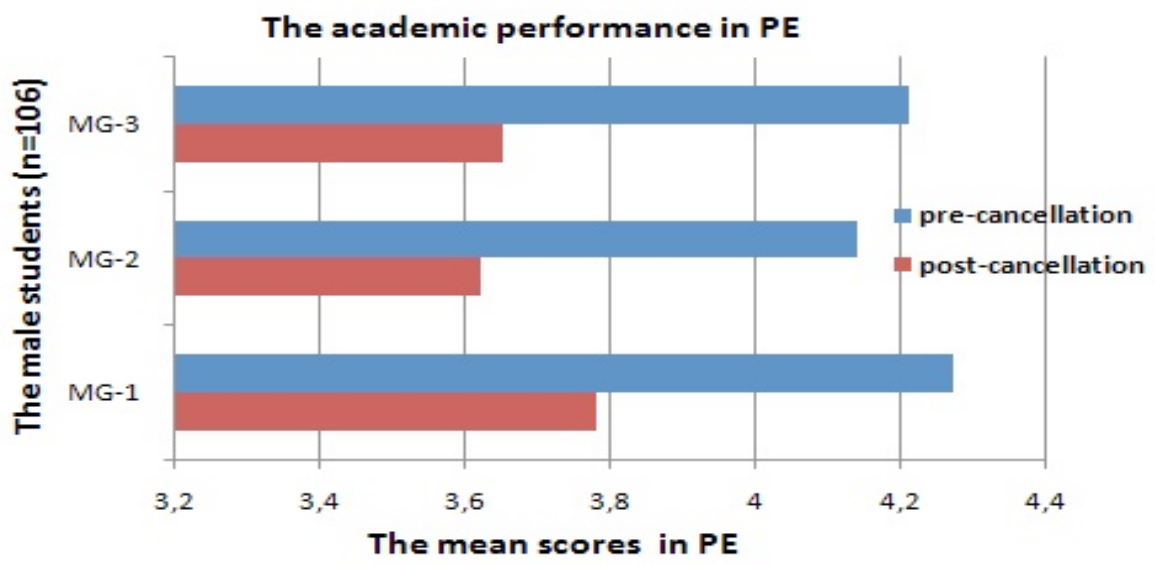

Fig. 1. The changes in academic performance in PE in male participants.

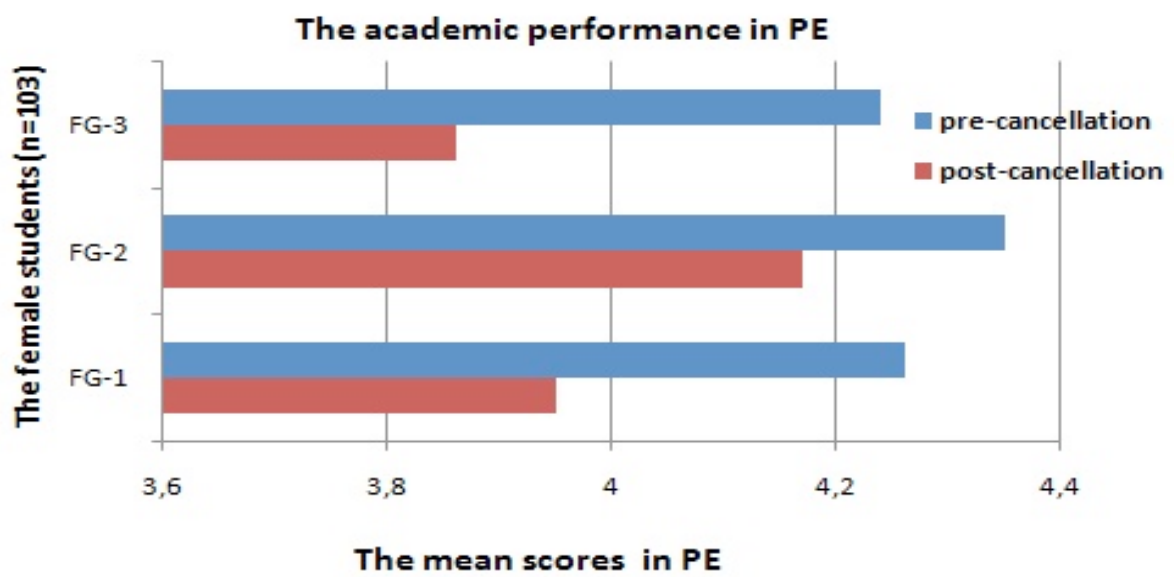

Fig. 2. The changes in academic performance in PE in female participants.

\section{Discussion}

The university closure and cancellation of face-to-face PE classes due to the COVID-19 pandemic decreased overall and sport/fitness PA level in all participants (male and female students). The findings testify a significant decrease in overall PA and sport/fitness PA for university students during the COVID-19 pandemic. This is in line with previous investigations, which showed that during the COVID-19 pandemic the student population decreased their PA levels $[17 ; 21]$. Luciano et al, state that during lockdown, Italian medicine students reduced their total PA and increased sedentary behaviour [18]. In our study, despite a general consistent reduction in overall PA level, a part of the sample (medicine students) was able to maintain significantly $(\mathrm{p} \leq 0.05)$ higher overall PA level. Galle et al, showed that this was associated with age, parents' education, previous PA levels, and with female gender and university attended [21]. All participants (male and female students) had similar indicators of chronological age, overall and sport/fitness PA level in our research. The university closure, transition to distance learning and cancellation of face-to-face PE classes were general conditions for the sample. We can explain the robust advantage of medicine (male and female) students in overall PA level the volunteer activities of medical students in hospitals during the COVID-19 pandemic.

Barkley et al, have disseminated information that pandemic-related closure of facilities designed for PA and sports may disproportionately impact active students. Investigators state that the university closure decreased PA level in students who were the most active precancellation. Conversely, the less active pre-cancellation PA students significantly increased their overall PA level [17]. All students (male and female groups) had a similar overall and sport/fitness PA levels pre-cancellation of face-to-face PE classes in our research. The overall PA level in all participants in this sample (less than 60006500 minutes per week for male students and less than 4000-4500 minutes per week for female students) did not allow them in the high PA group [9]. All participants significantly reduced overall PA and sport/fitness PA level post-cancellation. We found that medicine (male and female) students had a higher overall PA level than other students' post-cancellation of face-to-face PE classes and university closure. It is possible that the overall amount of PA during the pandemic period in university students may be related to the specialty of education.

It is known that the general reduction in PA in student 
population during the COVID-19 pandemic was not accompanied by a corresponding increase in BMI [17]. It is possible that the negative effects of inactivity on BMI might have been balanced by healthier dietary habits [21]. In this regard, we specifically didn't investigate the changes of BMI of male and female participants during the research. If the COVID-19 pandemic persists it may be warranted to re-examine pandemic-related changes in BMI over a longer period of time.

Chang state that online learning offers a variety of solutions in a time when traditional learning has been disrupted due to the Covid-19 pandemic. This system of education gives the opportunity to maintain quality dissemination of knowledge, responsibility and reduced costs of time [23]. Malinauskas \& Pozeriene, has compared academic motivation between university students of traditional and online education in a new context during the COVID-19 pandemic. The findings indicated that students' intrinsic motivation scores were higher in online students than in students who attend traditional education [26]. Tilga et al, highlight the facilitative role of autonomy-supportive behaviour in a PE context in young individuals PA participation outside of school [27]. Radu et al, state that most of Romanian university students were satisfied with the distance learning taken by the university during the lockdown period [35]. The findings highlight a significant $(p \leq 0.05)$ decline in academic performance of all students regardless of gender and specialty of education in our research. Perhaps these results are related to less effective teacher-student communication in self-isolation during the COVID-19 pandemic, impossibility of performing most practical applications in PE, lack of socialization and other reasons. The most Russian university students are dissatisfied with the content of distance learning courses in PE (a significant volume of theoretical tasks), lack of motor training and lack of contact with PE teachers [31]. Significant number of Russian university students have a fairly meaningful position, considering that online PE learning is unproductive in nature, without the main physical activities and PE practical classes [30]. Osipov et al, state that the medicine students showed a higher level of adaptation to the distance learning in PE during the COVID-19 pandemic. It is possible this is related to the extensive experience in using electronic educational resources in the daily learning practice in medical education process [31]. There was a significant $(p \leq 0.05)$ difference between female groups (in favour of medicine female students) in mean grading scores in PE post-cancellation of face-to-face PE classes.

Any inferences made in the present study have some limitations, associated with the overall number of participants. All the PA rates were measured using self-reported questionnaires. Additionally, data were all self-reported and the survey required participants to recall past behaviours for four months. Future scientific research must attempt to utilize objective measures (e.g., personal activity trackers, fitness apps, home electronic scales) to assess PA level and behaviour even if in-person data collection is not possible for the time being [17]. The implementation of daily monitoring of overall PA and sport/fitness PA of young individuals must stimulate students to increase their daily, weekly and monthly PA level [38].

\section{Conclusion}

In this research, we have provided some evidence of the negative impact of a university closure, due to the COVID-19 pandemic, upon overall PA level, sport/ fitness PA level and academic performance in PE in a sample of university students. All participants (male and female students) significantly $(\mathrm{p} \leq 0.05)$ decreased overall PA and sport/fitness PA level, which confirms our hypothesis. However, it is important to note that the proportional decrease in overall PA for the male students was actually large, then decrease in overall PA for the female students was less, which doesn't support our other hypothesis. These results suggest that while the university closure may have created some barriers to participating in overall PA for some students it is possible that other aspects of the cancellation may have encouraged overall PA in other students. For example, medical students (male and female) had a significantly $(\mathrm{p} \leq 0.05)$ higher overall PA level, then other participants. Perhaps this is due to the volunteer activities of medical students in hospitals during the COVID-19 pandemic.

There was a significant drop in mean grading scores in PE post-cancellation of face-to-face PE classes in student population, which doesn't support our other hypothesis. Perhaps these findings are related to less effective PE teacher-student communication in self-isolation during the COVID-19 pandemic, impossibility of performing most practical applications in PE and large number of theoretical tasks, lack of socialization and other reasons. PE teachers and professionals must be implemented effective and efficient measures to improve the academic performance of online educational process in PE during the lockdown period.

The information collected in this research highlights the need for interventions of PA promotion targeted at the student population. The findings suggest that there is a need to promote regular physical activities in the context of home quarantine and self-isolation measures and increase awareness of university students to induce cogent avoidance of activities related to physical inactivity and sedentary behaviours during the COVID-19 pandemic.

\section{Acknowledgements}

We would like to thank the all male and female students who participated in our study.

\section{Conflicts of interest.}

The authors of the article declare that there is no conflict of interest. 


\section{References}

1. Warburton D, Bredin S. Health benefits of physical activity: a systematic review of current systematic reviews. Curr Opin Cardiol, 2017; 32(5): 541-556. https://doi.org/10.1097/HCO.0000000000000437

2. Viciana J, Mayorga-Vega D, Parra-Saldías M. Within and between-day differences in adolescents' objectively-measured physical activity and sedentary behavior. Kinesiology, 2019; 51(2): 227-237. https://doi.org/10.26582/k.51.2.13

3. Van Hecke L, Loyen A, Verloigne M, van der Ploeg $\mathrm{H}$, Lakerveld $\mathrm{J}$, Brug $\mathrm{J}$, et al. Variation in population levels of physical activity in European children and adolescents according to cross-European studies: A systematic literature review within DEDIPAC. Int $J$ Behav Nutr Phys Act, 2016; 13(1): Article no. 70. https://doi.org/10.1186/s12966-016-0396-4

4. Rahman E, Islam S, Bishwas S, Moonajilin S, Gozal D. Physical inactivity and sedentary behaviors in the Bangladeshi population during the COVID-19 pandemic: An online cross-sectional survey. Heliyon, 2020; 6(10): e05392. https://doi.org/10.1016/j.heliyon.2020.e05392

5. Biddle S, Petrolini I, Pearson N. Interventions designed to reduce sedentary behaviours in young people: a review of reviews. Br J Sports Med, 2014; 48(3): 182-186. https://doi.org/10.1136/bjsports-2013-093078

6. Kudryavtsev M, Kramida I, Osipov A. Influence of monitor bad habits on healthy lifestyle of students. Teoriya i Praktika Fizicheskoy Kultury, 2016; 6: 24-26. https://doi.org/10.15561/20755279.2016.0603

7. Carson V, Hunter S, Kuzik N, Gray C, Poitras V, Chaput $\mathrm{J}$, et al. Systematic review of sedentary behaviour and health indicators in school-aged children and youth: An update. Appl Physiol Nutr Metab, 2016; 41(6): S240-S265. https://doi.org/10.1139/apnm-2015-0630

8. Haverkamp B, Wiersma R, Vertessen K, van Ewijk H, Oosterlaan J, Hartman E. Effects of physical activity interventions on cognitive outcomes and academic performance in adolescents and young adults: A metaanalysis. $J$ Sports Sci, 2020; 38(23): 2637-2660, https://doi.org/10.1080/02640414.2020.1794763

9. Leuciuc F, Ghervan P, Popovici I, Benedek F, Lazar A, Pricop G. Social and educational sustainability of the physical education of Romanian students and the impact on their physical activity level. Sustainability, 2020; 12: 9231. https://doi.org/10.3390/su12219231

10. Enchenko I, Egorova N. Comparative analysis of the physical activity level in Europe and Russian Federation. Human Sport Medicine, 2020; 20(4): 103-110. https://doi.org/10.14529/hsm200412

11. Nagovitsyn R, Tutolmin A, Maksimov Y, Dimova I, Karoyan A, Skryabina, D, et al. Motivation for physical activity of people of different ages. Gazzetta Medica Italiana Archivio per le Scienze Mediche, 2019; 178(10): 799-806. https://doi.org/10.23736/S0393-3660.18.03965-7

12.Loginov S. Daily physical activity and sedentary (inactive) behaviour of adults from Surgut. Human Sport Medicine, 2019; 19(4): 70- 77. https://doi.org/10.14529/hsm190409

13.Osipov A, Ratmanskaya T, Nagovitsyn R, Zhuikova S, Iermakov $\mathrm{S}$. Increasing the level of cardiorespiratory and strength endurance of female students by means of mixed training (Kangoo-jumps fitness and resistance training). Phys Activ Rev, 2020; 8(2): 38-47. https://doi.org/10.16926/par.2020.08.20
14.Al Awamleh A. Self-comparison of athletes during times of COVID-19 pandemic. Sport Sci, 2020; 14(Suppl. 1): 93-99.

15.Dunton G, Do B, Wang S. Early effects of the COVID-19 pandemic on physical activity and sedentary behavior in children living in the U.S. BMCPublic Health, 2020; 20: 1351. https://doi.org/10.1186/s12889-020-09429-3

16.Cachón-Zagalaz J, Sánchez-Zafra M, Sanabrias-Moreno D, González-Valero G, Lara-Sánchez A, ZagalazSánchez M. Systematic review of the literature about the effects of the COVID-19 pandemic on the lives of school children. Front Psychol, 2020; 11: 569348. https://doi.org/10.3389/fpsyg.2020.569348

17.Barkley J, Lepp A, Glickman E, Farnell G, Beiting J, Wiet R, Dowdell B. The acute effects of the COVID-19 pandemic on physical activity and sedentary behavior in university students and employees. Int J Exerc Sci, 2020; 13(5): 13261339 .

18.Luciano F, Cenacchi V, Vegro V, Pavei G. COVID-19 lockdown: physical activity, sedentary behaviour and sleep in Italian medicine students. Eur J Sport Sci, 2020:1-10. https://doi.org/10.1080/17461391.2020.1842910

19. Cheval B, Sivaramakrishnan H, Maltagliati S, Fessler L, Forestier C, Sarrazin P, et al. Relationships between changes in self-reported physical activity, sedentary behaviour and health during the coronavirus (COVID-19) pandemic in France and Switzerland. J Sports Sci, 2020:1-6. https://doi.org/10.1080/02640414.2020.1841396

20.AmettaA,Francavilla V,Polito R, Monda M, MessinaA, Monda V, etal.Physical activity as protective factor against COVID-19 disease. J Hum Sport Exerc, 2020; 15(4proc): S987-S991. https://doi.org/10.14198/jhse.2020.15.Proc4.01

21.Galle F, Sabella E, Ferracuti S, De Giglio O, Caggiano G, Protano C, et al. Sedentary behaviors and physical activity of Italian undergraduate students during lockdown at the time of CoViD-19 pandemic. Int $J$ Environ Res Public Health, 2020; 17(17): 6171. https://doi.org/10.3390/ijerph17176171

22.Sallis J, Adlakha D, Oyeyemi A, Salvo D. An international physical activity and public health research agenda to inform coronavirus disease-2019 policies and practices. J Sport Health Sci, 2020; 9(4): 328-334. DOI:10.1016/j. jshs.2020.05.005

23.Chang H. Online learning in Pandemic times. RevRomânească Pentru Educ Multidimens, 2020; 12(2Sup1): 111-117. https://doi.org/10.18662/rrem/12.2Sup1/296

24.Pérez-Turpin J, Gomis-Gomis M. Physical activity and sport: post-COVID-19. J Hum Sport Exerc, 2020; 15(2): 476-477. https://doi.org/10.14198/jhse.2020.152.21

25.Mishra L, Gupta T, Shree A. Online teaching-learning in higher education during lockdown period of COVID-19 pandemic. Int J Educ Res, 2020; 1: 100012. https://doi.org/10.1016/j.ijedro.2020.100012

26. Malinauskas R, Pozeriene J. Academic motivation among traditional and online university students. Eur J Contemp Educ, 2020; 9(3): 584-591. https://doi.org/10.13187/ejced.2020.3.584

27.TilgaH,Kalajas-TilgaH,HeinV,RaudseppL,KokaA.Howdoes perceived autonomy-supportive and controlling behaviour in physical education relate to adolescents' leisure-time physical activity participation? Kinesiology, 2020; 52(2): 265-272. https://doi.org/10.26582/k.52.2.13

28.Nagovitsyn R, Vaganova O, Kutepov M, Martyanova L, Kosenovich O, Moeseev Y, et al. Interactive technologies in developing student's motivation in physical education and sport. Int J Appl Exerc Physiol, 2020; 9(6): 72-79. 
29.Gonzalez T, de la Rubia M, Hincz K, Comas-Lopez M, Subirats L, Fort S, et al. Influence of COVID-19 confinement on students' performance in higher education. PLoS ONE, 2020; 15(10): e0239490. https://doi.org/10.1371/journal.pone.0239490

30.Pokrovskaya T, Usupov R, Titova E, Zhuravleva Y. Distance learning in physical education and sports discipline in terms of self-isolation. Teoriya i Praktika Fizicheskoy Kultury, 2020; 11: 65-67.

31.Osipov A, Kudryavtsev M, Galimova A, Plotnikova I, Skurikhina N. How can distance learning be used in the physical education of students? Rev Românească Pentru Educ Multidimens, 2020; 12(2Sup1): 77- 85. https://doi.org/10.18662/rrem/12.2Sup1/292

32.Silva R, Vera Lucia F, SilvaA. Distance learning for teaching in physicaleducation.Motriz:RevEducFís, 2019;25(1):e101832. https://doi.org/10.1590/s1980-6574201900010002

33.Lavrin G, Sereda O, Kucher V, Grygus I, Zukow W. The Results of student's survey on models of physical education in universities and motivations to encourage for active participation in physical education. Int J Appl Exerc Physiol, 2019; 8(2): 1-5. https://doi.org/10.30472/ijaep.v8i2.391
34.Mozolev O, Polischuk O, Kravchuk L, Tatarin O, Zharovska O, Kazymir V. Results of monitoring the physical health of female students during the COVID-19 pandemic. $J$ Phys Educ Sport, 2020; 20(suppl. 6): 3280-3287. https://doi.org/10.7752/jpes.2020.s6445

35.Radu M, Schnakovszky C, Herghelegiu E, Ciubotariu V, Cristea I. The impact of the COVID-19 pandemic on the quality of educational process: A student survey. Int $J$ Environ Res Public Health, 2020; 17: 7770. https://doi.org/10.3390/ijerph17217770

36.Borodavko L, Silkin N, Shakhmatov A, Chelysheva O. Organization of education using modern distance learning technologies in the context of the COVID-19 pandemic (on the example of Russian law schools). Amazonia Investiga, 2020; 9(33): 51-58. https://doi.org/10.34069/AI/2020.33.09.6

37.Banku T, Yakimovich E, Konoplev V, Kharchenko E, Panin E. Effect of distance learning of students' physical condition. Teoriya i Praktika Fizicheskoy Kultury, 2020; 5: 40-42.

38. Nagovitsyn R, Osipov A, Loginov D, Prikhodov D, Vapaeva A. Individual system of self-monitoring of the daily motor activity of athletes. J Hum Sport Exerc, 2020; 15(2proc): S118-S128. https://doi.org/10.14198/jhse.2020.15.Proc2.01

\section{Information about the authors:}

Aleksander Yu. Osipov; http://orcid.org/0000-0002-2277-4467; ale44132272@yandex.ru; Siberian Federal University, Krasnoyarsk State Medical University named after professor V.F. Voyno-Yasenetsky; Krasnoyarsk, Russian Federation.

Tatyana I. Ratmanskaya; http://orcid.org/0000-0001-9544-1674; tanyabaulina@rambler.ru; Siberian Federal University; Krasnoyarsk, Russian Federation.

Elena A. Zemba; http://orcid.org/0000-0003-1656-3791; zembaelena@rambler.ru; Reshetnev Siberian State University of Science and Technology; Krasnoyarsk, Russian Federation.

Vladimir Potop; http://orcid.org/0000-0001-8571-2469; vladimir_potop@yahoo.com; Ecological University of Bucharest; Bucharest, Romania.

Mikhail D. Kudryavtsev; http://orcid.org/0000-0002-2432-1699; kumid@yandex.ru; Siberian Federal University, Reshetnev Siberian State University of Science and Technology; Krasnoyarsk, Russian Federation.

Roman S. Nagovitsyn; (Corresponding Author); http://orcid.org/0000-0003-4471-0875; gto18@mail.ru; Glazov State Pedagogical Institute named after V.G. Korolenko; Glazov, Russian Federation.

Cite this article as:

Osipov AYu, Ratmanskaya TI, Zemba EA, Potop V, Kudryavtsev MD, Nagovitsyn RS. The impact of the universities closure on physical activity and academic performance in physical education in university students during the COVID-19 pandemic. Physical Education of Students, 2021;25(1):20-27. https://doi.org/10.15561/20755279.2021.0103

This is an Open Access article distributed under the terms of the Creative Commons Attribution License, which permits unrestricted use, distribution, and reproduction in any medium, provided the original work is properly cited http://creativecommons.org/licenses/by/4.0/deed.en

Received: 09.12.2020

Accepted: 29.01.2001; Published: 26.02.2021 